\title{
Association of Mediterranean diet, dietary supplements and alcohol consumption with breast density among women in South Germany: a cross-sectional study
}

\author{
Olga Voevodina', Christian Billich², Birke Arand ${ }^{3}$ and Gabriele Nagel ${ }^{1 *}$
}

\begin{abstract}
Background: Effects of dietary factors, such as adherence to Mediterranean diet, multivitamin-multimineral supplements use and alcohol consumption on mammographic breast density, an important biomarker of breast cancer risk, are not sufficiently consistent to elaborate preventive recommendations. This study aims to investigate the association between current diet and mammographic density.

Methods: We performed a cross-sectional study in 424 pre- and post-menopausal women aged 21 to 84 years. Current Mediterranean dietary pattern, multivitamin-multimineral supplements use, alcohol consumption and potential confounders were assessed with a self-administered questionnaire in the University Hospital Ulm (2007-2008). Radiologists evaluated mammographic density according to the American College of Radiology (ACR) classification, which was summarized in low $=$ ACR1/2 and high $=$ ACR3/4 mammographic density. Logistic regression models were used to assess the association between current diet and mammographic density.

Results: Adherance to Mediterranean dietary pattern was inversely associated with mammographic density in the models adjusted for age and BMI (per 1 unit increase of score OR 0.95; 95\% $\mathrm{Cl} 0.90-0.997$ ). Current use of multivitamin-multimineral supplements was also inversely associated with mammographic density (OR 0.53; $95 \% \mathrm{Cl}$ 0.34-0.83). Further adjustment revealed similar point estimates but the associations were no longer statistically significant. Compared to non-drinkers, excessive alcohol consumption ( $<10 \mathrm{~g} / \mathrm{d})$ was positively associated with mammographic density (OR 1.47; 95\%Cl 0.82-2.63).

Conclusions: Our results show that dietary factors are associated with mammographic density. Adherence to Mediterranean diet and current use of multivitamin-multimineral supplements could be inversely associated with mammographic density and may suggest a protective effect against breast cancer, whereas high alcohol consumption was associated with increased mammographic density.
\end{abstract}

Keywords: Mammographic breast density, Diet, Supplements, Alcohol, Breast cancer

\footnotetext{
* Correspondence: Gabriele.Nagel@uni-ulm.de

${ }^{1}$ Institute of Epidemiology and Medical Biometry, Ulm University, Helmholtzstr. 22, Ulm 89081, Germany

Full list of author information is available at the end of the article
} 


\section{Background}

Breast cancer is a malignant tumor, originating from the breast's glandular tissue. It is one of the most frequent malignant tumors in most Western countries [1]. Breast cancer is a common cause of death of women between 40 and 50 years of age [2]. Risk factors for breast cancer are among many others: age, parity, hormone replacement therapy, menopausal status, and family history of breast cancer [3]. Increased mammographic density is an important independent risk factor for breast cancer [4]. High breast density is consistent with the breast's amount of fibroepithelial tissue [5], which appears as radiographic dense on mammograms [5]. The biological pathways linking high mammographic density with breast cancer still need further investigation.

Mammography is a radiological method for the measurement of breast density [6] and for early detection of breast cancer [7]. Different scales can be used to evaluate the mammographic density. The first classification was established by Wolfe in 1976 [8]. Another classification, BI-RADS with ACR-categories, was developed by the American College of Radiology and published in 1993 [7]. It helped to standardize mammography reports, breast density evaluation and the interpretation of mammograms [7]. Other methods to quantify breast density, like ultrasound and magnetic resonance imaging, also applied in breast diagnostic.

Breast density may be a possible surrogate marker in the prevention of breast cancer [9]. It is important to identify factors which modify mammographic density and thereby might be useful as a basis of preventive interventions. There is evidence that exogenous hormones, a larger number of live births, age, body-mass-index and other factors can alter the pattern of breast density on a mammogram [3]. Especially adherence to Mediterranean dietary pattern, intake of multivitamin-multimineral supplements and alcohol consumption could be established as basic interventions in prevention of high mammographic density in the future $[4,9]$. These factors show an association with breast cancer risk and more easily modifiable than reproductive factors. Alcohol consumption may have an influence on breast neoplasm formation [10]. It remains unclear whether alcohol consumption increases the mammographic density, compared to non-drinkers. Breast cancer prevalence is lower in Mediterranean populations than in northern European ones [11]. The differences in prevalence could be explained by different dietary patterns in Mediterranean and northern European populations. A Mediterranean dietary pattern is characterized by regular consumption of fruit, vegetables and olive oil [11]. The northern European diet is characterized by high consumption of meat and saturated fatty acids [11]. It may be important to clarify whether an association between the mammographic density of breast tissue and an adherence to Mediterranean diet exists.
This study aims to investigate the association between Mediterranean dietary pattern, current intake of multivitamin-multimineral supplements, and alcohol consumption with mammographic density.

\section{Methods \\ Study population}

Between April 2007 and September 2008494 women aged 21 to 84 years, who underwent mammography at the breast center in University Hospital Ulm, were recruited in this cross-sectional study. After informed consent they completed a self-administered questionnaire. From the statistical analysis 65 participants were excluded due to history of breast ablation and breast cancer and 5 participants filled in the questionnaire twice. Thus 424 women remained for the analysis.

A study protocol was approved by the ethics committee of the medical faculty of Ulm University.

\section{Data assessment}

The questionnaire assessed socio-demographic characteristics, including date of birth, nationality, body weight, height and education. Furthermore, participants were asked to comment on their consumption of food, beverages, physical activity and their smoking status. The food questionnaire of this study was partially adapted from the food questionnaire of the Million Women Study [12]. The choice of the components was based on the hypothesis that a low consumption of "unhealthy" food, such as meat (contains saturated fatty acids) [13] and a high consumption of "healthy" food, such as fruits (contain antioxidants) [14] protect against a high mammographic density as indicator for higher breast cancer risk. Participants provided information on reproductive factors, such as age at menarche, menopausal status and parity, and family history of breast cancer. Data on hormone replacement therapy, biopsy of breast and past medical history was also included.

In this study, we collected information of the supplementary intake of vitamins and minerals both individually and combined. Due to the small numbers on single vitamin and mineral use, we investigated the association between intake of multivitamin-multimineral supplements and mammographic density. The corresponding question in our questionnaire was: "Do you take vitamins, minerals or dietary supplements regularly?"

Data on the consumption of wine, beer and spirits beverages in glasses per week has been collected to assess a drinking of alcoholic beverages. We calculated how much alcohol in g (gram) each woman consumed according to conversions described in other German studies $[15,16]$. The following conversions were made:

wine: 1 glass $=0.25$ liter [15].

beer: 1 glass $=0.3$ liter . 
spirits beverage: 1 glass $=0.02$ liter .

1 liter wine $=100 \mathrm{~g}$ alcohol, and

1 liter beer $=40 \mathrm{~g}$ alcohol [16].

There were $25 \mathrm{~g}$ alcohol in 1 glass wine; $12 \mathrm{~g}$ alcohol in 1 glass bier and $6.2 \mathrm{~g}$ alcohol in 1 glass spirits beverage [16]. On the basis of this data, we calculated the total alcohol consumption (wine, beer and spirits beverage) per day (d) in gram for each participant. We created quantitative (increase per $10 \mathrm{~g} / \mathrm{d}$ ) and qualitative variables to analyze alcohol consumption. Categorized variable included four classes: > $10.0 \mathrm{~g} / \mathrm{d}$ total alcohol; 5.0 - $10.0 \mathrm{~g} / \mathrm{d}$ total alcohol; $0.1-5.0 \mathrm{~g} / \mathrm{d}$ total alcohol and $0 \mathrm{~g} / \mathrm{d}$ total alcohol.

We selected the dietary components contributing to a score based on other studies of adherence to Mediterranean diet. Based on other studies on the adherence to Mediterranean dietary pattern $[11,17]$ we selected the dietary components in our study. The following foods were included: boiled and raw vegetables, fruit, fish, nuts and olive oil (pro-Mediterranean diet); butter, beef, pork, sausages, ham, hamburger and lemonade/soft drinks (contra-Mediterranean diet). Points were assigned for proMediterranean food: low consumption $=1$ point, regular consumption $=2$ points, frequent consumption $=3$ points. Points for contra-Mediterranean food were reversed: low consumption $=3$ points, regular consumption $=2$ points, frequent consumption $=1$ point. In cases of no consumption or where no information was provided, 0 points were given. In total, a maximum of 29 points could be achieved. High score indicates adherence to Mediterranean diet.

As potential confounders were considered: physical activity at recruitment (yes/no), Body-Mass-Index (BMI) at recruitment $\left(\mathrm{kg} / \mathrm{m}^{2}\right)$, ever use of hormone replacement therapy (HRT) (yes/no), menopausal status at recruitment (proxy variable with premenopausal $(<50)$ and postmenopausal $(\geq 50)$ women), age at recruitment (years), mother with history of breast cancer (yes/no), school education (9 years of school/13 years of school), ever use of oral contraceptives (yes/no), age at menarche (years), smoker at recruitment (yes/no), ever breast feeding (yes/no), number of live births (quantitative variable; $0,1,2,3,4$ or 5 live births), age at the first birth (quantitative variable; years), alcohol consumption at recruitment (yes/no) if not exposure variable.

\section{Mammographic density assessment}

Breast density was assessed by two radiologists of the University Hospital Ulm applying the classification of the American College of Radiology (ACR) including four categories: ACR 1 =almost entirely fat, glandular tissue $<25 \%$; ACR 2 = scattered fibroglandular densities (ca. $25-50 \%$ of the breast); ACR $3=$ heterogeneously breast dense (ca. $51-75 \%$ of the breast); ACR $4=$ extremely dense ( $>75 \%$ of the breast) [7]. For the analyses the ACR categories were combined: category ACR 1/2 (including ACR 1 and ACR 2) means lower density and category ACR 3/4 (including ACR 3 und ACR 4) means higher density of breast. The measurement of the left breast was incorporated into the statistical analysis. Breast densities were assessed by two radiologists separately to determine inter-rater reliability. The differences in assessment of mammographic density between these two raters were calculated with the kappa-value. According to Altman's interpretation of kappa-values [18], the inter-rater variability assessed by kappa statistics showed moderate agreement (0.48) for ACR classes, but for the categories ACR1/2 and ACR 3/4 good agreement (0.61) was found.

\section{Statistical analysis}

The $X^{2}$-test, the $t$-test and the Wilcoxon-test were used to analyze the significance of different frequencies and distribution, respectively. We defined the level of statistical significance as 0.05 . We used these tests to investigate the significance of relationships between possible confounders (such as BMI, education, etc.) and either the target variable (mammographic density) or influencing variables (such as current intake of multivitaminmultimineral supplements, current alcohol consumption and Mediterranean dietary pattern). Tests for trend across quartiles were performed by assigning the mean level within specific quartiles of alcohol intake to all individuals in that quartile, and using this as a continuous variable in a linear regression. Logistic regression models were fitted to obtain Odds Ratios (ORs) with 95\% confidence intervals (95\%CIs) for high mammographic density. Additionally interactions between influencing variables and the target variable were tested. Variables, which were identified as potential confounders because they had a biological plausibility and statistically significant relationships with the target variable and/or influencing variables, were tested with manual step-by-step regression. A variable showed an effect and was identified as a confounder, if it had changed estimator more than $10 \%$. The parsimonious models were adjusted for age and BMI based on results of the manual step-bystep regression and/or the biological plausibility. These models were computed stratified by smoking status in order to account for differential association according to hormonal and oxidative stress, respectively. Also the fully adjusted models were calculated, adjusted for physical activity, BMI, HRT use, menopausal status, age, mother with history of breast cancer, school education, ever use of oral contraceptives, age at menarche, smoker at recruitment, number of live births, alcohol consumption. Statistical analysis was assessed with the Analyst Interface of the SAS (Statistical Analysis System) Version 9.2. 


\section{Results}

The study sample is characterized in Table 1 . There were 150 premenopausal and 274 postmenopausal women included in the study. Mean age of the study sample was 54 (SD 10.5) years. Most women were German (95\%) and had completed at least 9 years of school (71\%). More than $50 \%$ of the women were normal weight (median $=24.46 \mathrm{~kg} / \mathrm{m}^{2}$ ) and most women were physically active (76\%). Overall, $80 \%$ women had ever taken oral contraceptives and 30\% hormone replacement therapy. $80 \%$ of the women had ever breastfed.

There were $35 \%$ of the women who consumed multivitamin-multimineral supplements. Alcohol consumption was reported by $67 \%$ and smoking by $12 \%$. Most women consumed wine (61\%). High scores of Mediterranean diet score (more than 24 points) indicating adherence to Mediterranean diet was observed in $25 \%$ of the women. Overall, $56 \%$ of the women had high mammographic density

Table 1 Characteristics of study sample

\begin{tabular}{|c|c|c|c|c|c|c|}
\hline & $\mathrm{n}^{*}$ & Mean & SD & Min. & Max. & Median \\
\hline Age (at recruitment) (years) & 424 & 53.98 & 10.50 & 21.00 & 84.00 & 54.00 \\
\hline BMI (at recruitment) $\left(\mathrm{kg} / \mathrm{m}^{2}\right)$ & 420 & 25.23 & 4.86 & 17.31 & 65.76 & 24.46 \\
\hline Age at menarche (years) & 407 & 13.21 & 1.49 & 10.00 & 19.00 & 13.00 \\
\hline Age at the first birth (years) & 343 & 25.62 & 5.10 & 16.00 & 45.00 & 25.00 \\
\hline \multirow[t]{2}{*}{ Number of live births } & 406 & 1.70 & 1.05 & 00.00 & 5.00 & 2.00 \\
\hline & & ute freq & ve freq & & & \\
\hline
\end{tabular}

(n)

Physical activity (at recruitment)

$$
\text { yes }
$$$$
\text { no }
$$

Alcohol consumption (at recruitment)

$$
\text { yes }
$$$$
\text { no }
$$

Smoker (at recruitment)

$$
\begin{gathered}
\text { yes } \\
\text { no }
\end{gathered}
$$

School education

$$
\begin{aligned}
& 9 \text { years of school } \\
& 13 \text { years of school }
\end{aligned}
$$

HRT (ever)

$$
\begin{gathered}
\text { yes } \\
\text { no }
\end{gathered}
$$

Use of oral contraceptives (ever)

$$
\text { yes }
$$$$
\text { no }
$$

Mother with history of breast cancer

$$
\text { yes }
$$

no

Menopausal status

$$
\begin{gathered}
\text { premenopausal }(<50) \\
\text { postmenopausal }(\geq 50)
\end{gathered}
$$

Breast feeding (ever)

424

424

424

424

339
424

424

$324 \quad 76$

$100 \quad 24$

$298 \quad 71$

$119 \quad 29$

$128 \quad 30$

$296 \quad 70$

$\begin{array}{ll}339 & 80 \\ 85 & 20\end{array}$

$\begin{array}{ll}68 & 16 \\ 356 & 84\end{array}$

$\begin{array}{ll}150 & 35 \\ 274 & 65\end{array}$

yes $\quad 272 \quad 80$

no

$67 \quad 20$

Abbreviations: $n$, number of observations; $S D$, standard deviation; BMI, body-mass-index; min., minimum; max, maximum; $k g$, kilogram; $m^{2}$, square meter; $H R T$, hormone replacement therapy.

*Numbers may not add up to 424 due to missing values. 
(ACR3/4). Among premenopausal women mammographic dense breast parenchyma was more prevalent (73\%) than among postmenopausal women (46\%).

Adherence to the Mediterranean diet was inversely associated with mammographic density adjusted for age and BMI (per 1 unit increase: OR 0.95; 95\%CI 0.90-0.997) (OR 0.97; 95\%CI 0.91-1.02) (Table 2) and in the parsimonious model, of which the later reached statistical significance. Stratification by smoking status in this model revealed a statistically significant association between adherence to Mediterranean dietary pattern and mammographic density (OR 0.95; 95\%CI 0.90-0.999) among non-smoking women. No association was found in smoking women (OR 0.97; $95 \% \mathrm{CI} 0.80-1.19)$. This interaction with smoking was not significant (p-value 0.634)

The results of the multivariate analyses for multivitaminmultimineral supplements are displayed in Table 3. The consumption of multivitamin-multimineral supplements was significantly associated with reduced mammographic density in both the fully adjusted model (OR 0.61; 95\% CI 0.38-0.97) and also in the parsimonious model. In postmenopausal women the association was significant (OR 0.51 ; 95\%CI $0.30-0.88$ ), but not among premenopausal women (OR 0.58; 95\%CI 0.25-1.36). Stratification by smoking status revealed a statistically significant positive association between multivitamin-multimineral supplements and mammographic density among nonsmoking women only (OR 0.52; 95\%CI 0.33-0.84). However, the interaction between multivitamin-multimineral supplements and smoking status was not significant ( $\mathrm{p}$-value $=0.84)$.

The results between alcohol consumption and mammographic density are displayed in Table 4 . In the parsimonious models, no statistically significant association was

Table 2 Association between Mediterranean diet score and high mammographic density (ACR 3/4)

\begin{tabular}{|c|c|c|}
\hline $\begin{array}{l}\text { Mediterranean diet score } \\
\text { (increase per increment) }\end{array}$ & & \\
\hline & $\mathrm{OR}^{*}$ & $95 \% \mathrm{Cl}$ \\
\hline \multirow[t]{2}{*}{ Pre- and postmenopausal $\left(n^{* *}=392\right)$} & 0.97 & $(0.91-1.02)$ \\
\hline & $\mathrm{OR}^{* * *}$ & $95 \% \mathrm{Cl}$ \\
\hline Pre- and postmenopausal $\left(\mathrm{n}^{* *}=420\right)$ & 0.95 & $(0.90-0.997)$ \\
\hline Premenopausal ( $n=149$ ) & 0.99 & $(0.89-1.10)$ \\
\hline Postmenopausal $(\mathrm{n}=271)$ & 0.94 & $(0.89-0.99)$ \\
\hline Smoker $(n=51)$ & 0.97 & $(0.80-1.19)$ \\
\hline Nonsmoker $(n=369)$ & 0.95 & $(0.90-0.999)$ \\
\hline
\end{tabular}

Abbreviations: $n$, number of observations; OR, Odds Ratio; $95 \% \mathrm{Cl}, 95 \%$ confidence interval.

* Fully adjusted models were adjusted for physical activity, BMI, HRT, menopausal status, age, mother with history of breast cancer, school education, ever use of oral contraceptives, age at menarche, smoker at recruitment, number of live births, alcohol consumption.

**Numbers may not add up to 424 due to missing values.

*** Parsimonious models were adjusted for age and BMI at recruitment.
Table 3 The association between intake of multivitaminmultimineral supplements and high mammographic density (ACR 3/4) Multivitamin-multimineral supplements
(current intake)

$\mathrm{OR}^{*} \quad 95 \% \mathrm{Cl}$

Pre- and postmenopausal $\left(\mathrm{n}^{* *}=392\right)$

$\begin{array}{ccc}\text { no } & 1 \text { (ref.) } & \\ \text { yes } & 0.61 & (0.38-0.97) \\ & \text { OR }^{* * *} & \mathbf{9 5 \% \mathbf { C l }}\end{array}$

Pre- and postmenopausal $\left(\mathrm{n}^{* *}=420\right)$

$\begin{array}{ccc}\text { no } & 1 \text { (ref.) } & \\ \text { yes } & 0.53 & (0.34-0.83)\end{array}$

Premenopausal $(n=149)$

$\begin{array}{ccc}\text { no } & 1 \text { (ref.) } & \\ \text { yes } & 0.58 & (0.25-1.36)\end{array}$

Postmenopausal $(n=271)$

$\begin{array}{lcc}\text { no } & 1 \text { (ref.) } & \\ \text { yes } & 0.51 & (0.30-0.88)\end{array}$

Abbreviations: $n$, number of observations; OR, Odds Ratio; $95 \% C l, 95 \%$ confidence interval.

* Fully adjusted models were adjusted for physical activity, BMI, HRT, menopausal status, age, mother with history of breast cancer, school education, ever use of oral contraceptives, age at menarche, smoker at recruitment, number of live births, alcohol consumption.

**Numbers may not add up to 424 due to missing values.

*** Parsimonious models were adjusted for age and BMI at recruitment.

Table 4 Association between alcohol consumption and a high mammographic density (ACR 3/4)

Alcohol consumption classes (current intake)

$\mathrm{OR}^{*} \quad 95 \% \mathrm{Cl}$

Pre- and postmenopausal $\left(n^{* *}=392\right)$

$\begin{array}{rcc}\text { Non-consumer } & 1 \text { (ref.) } & \\ 0.1-5.0 \mathrm{~g} / \mathrm{d} & 1.77 & (0.92-3.40) \\ 5.0-10.0 \mathrm{~g} / \mathrm{d} & 1.85 & (0.98-3.48) \\ >10.0 \mathrm{~g} / \mathrm{d} & 1.94 & (1.02-3.71) \\ & \text { OR }^{* * *} & \mathbf{9 5 \% C l}\end{array}$

Pre- and postmenopausal $\left(\mathrm{n}^{* *}=420\right)$

$$
\begin{array}{rcr}
\text { Non-consumer } & 1 \text { (ref.) } & \\
0.1-5.0 \mathrm{~g} / \mathrm{d} & 1.48 & (0.82-2.67) \\
5.0-10.0 \mathrm{~g} / \mathrm{d} & 1.64 & (0.91-2.95) \\
>10.0 \mathrm{~g} / \mathrm{d} & 1.47 & (0.82-2.63)
\end{array}
$$

Abbreviations: $n$, number of observations; OR, Odds Ratio; $95 \% \mathrm{Cl}, 95 \%$ confidence interval; $g$, gram; $d$, day.

* Fully adjusted models were adjusted for physical activity, BMI, HRT, menopausal status, age, mother with history of breast cancer, school education, ever use of oral contraceptives, age at menarche, smoker at recruitment, number of live births, alcohol consumption.

**Numbers may not add up to 424 due to missing values.

*** Parsimonious models were adjusted for age and BMI at recruitment. 
found between alcohol consumption and mammographic density in pre- and postmenopausal women (alcohol consumption $(>10 \mathrm{~g} / \mathrm{d}$ ) versus no consumption (OR 1.47; 95\% CI 0.82-2.63). In the fully adjusted model, a significant association emerged (OR 1.94; 95\%CI 1.02-3.71).

\section{Discussion}

Adherence to Mediterranean diet was inversely associated with mammographic density. Our data show further that the consumption of multivitamin-multimineral supplements is associated with a reduction in mammographic density. High levels of alcohol consumption may be related to higher mammographic density.

\section{Mediterranean diet}

In line with former research on diet and mammographic density, we found an inverse association between the adherence to Mediterranean diet score and mammographic density $[11,19,20]$. Our results did not change by additional adjustment for alcohol consumption and multivitamin-multimineral supplements.

Previous analyses of single food groups and mammographic density showed that components of the Mediterranean diet such as vegetables and olive oil could be inversely associated [20]. Consistent with our finding of an inverse association among postmenopausal women, prospective studies on breast cancer have shown that conformity to Mediterranean diet is associated with reduced breast cancer risk among postmenopausal women $[17,21]$. However, among postmenopausal women in Japan intakes of protein, total fat, and saturated fat were significantly positively associated with percentage of mammographic density [22], while carbohydrates were inversely associated. For components of the Mediterranean diet biological mechanisms have been described related to antioxidants, phytoestrogens and fatty acids [23]. In an observational study inverse associations between phytoestrogens and mammographic density have been reported [24].

In contrast to Tseng et al. (2008) we observed a statistically significant inverse association of Mediterranean diet score with mammographic density among nonsmoking women.

\section{Multivitamin-multimineral supplements}

Our findings of an inverse association between the current use of multivitamin-multimineral supplements and mammographic density in postmenopausal women are in contrast to results from a case-control study showing that multivitamin-multimineral supplement use is associated with higher breast density among premenopausal women [25]. Our results did not substantially change by additional adjustment for educational levels or other adjustment variables. Due to the antioxidant property of vitamins and minerals an inverse association seems to be biologically plausible [26].

Epidemiological studies on diet have shown inverse associations between vitamin $\mathrm{D}$ intake and mammographic density [27]. For the intake of vitamin $\mathrm{C}$ and $\mathrm{E}$ positive associations with mammographic density [19] and inverse associations for vitamin $\mathrm{C}$ intake have been reported [20].

Women who take multivitamin-multimineral supplement may have a healthier lifestyle than others. However, differences in the composition of the multivitaminmultimineral supplement pills and the inclusion of potential confounders could have influenced the associations. Data on use of vitamin and mineral supplements and its combination are scarce [25].

\section{Alcohol consumption}

In our study, current alcohol intake of more than $10 \mathrm{~g} / \mathrm{d}$ was associated with high mammographic density in preand postmenopausal women. Results from prospective [20,28], case-control [29] and cross-sectional [30] studies have shown that increased alcohol intake is associated with mammographic more dense breast parenchyma. However, also no association between alcohol intake and mammographic density was found in a cross-sectional study [31]. Flom et al. investigated alcohol beverages and found that particularly beer and white wine consumption may increase mammographic density [28].

There is evidence linking alcohol by Insulin-like growth factor (IGF) and Insulin-like growth factor binding protein (IGFBP)-3 to mammographic density [32,33]. In addition, alcohol increases estrogen levels in blood [34] which were found to increase mammographic density [35].

\section{Strengths and limitations}

One potential limitation of this study is that measurement error is inherent in dietary assessment. However, our data for alcohol were consistent with other data from Germany [16], and for dietary variables long-term reproducibility was fairly [36] indicating that dietary habits are stable over longer time intervals.

In the Mediterranean diet score in cases with no information on food items (e.g. for fish), 0 points were given. However, exclusion of individuals without information revealed similar results in the fully adjusted model without elimination of these women.

Since a cross-sectional study was performed, we cannot appraise the time sequence of the associations. The data on exposure variables were collected retrospectively, which may have introduced recall bias. However, it is likely to be non differential.

The assessment of the mammograms by experienced radiologists is one of the strengths of our study. In 
addition, we calculated the fully adjusted and the parsimonious models which revealed similar results but only statistical significance was reached in the parsimonious models.

The inter-rater reliability for the analyzed categories of ACR classification as indicator for mammographic density was good. ACR classification of mammographic density is widely applied and it has been shown that it is correlated with more refined measurement methods [8]. Information on reproductive and use of exogenous hormones has been collected by a standardized questionnaire. However, in our data these variables did not substantially affect the estimates.

\section{Conclusions}

In summary, this study suggests that adherence to the Mediterranean diet and current use of multivitamin-multimineral supplements are associated with mammograhically less dense breast parenchyma as intermediary marker of breast cancer risk. Further studies are needed to investigate the value of dietary intervention in the prevention of breast cancer.

\section{Abbreviations}

BI-RADS: The breast imaging reporting and data system; ACRcategories: Categories of the American College of Radiology; BMI: Bodymass-index; HRT: Hormone replacement therapy; SAS: Statistical analysis system; IGF: Insulin-like growth factor; IGFBP: Insulin-like growth factor binding protein.

\section{Competing interests}

The authors declare that they have no competing interests.

\section{Authors' contributions}

$\mathrm{GN}, \mathrm{AB}$ conception of the study; CB, BA data collection; OV, GN data analyses; OV wrote the first draft, which was refined by contributions of $C B$, BA, GN. All authors read and approved the final manuscript.

\section{Acknowledgements}

We thank Daniela Oesterle and Claudia Leis for their excellent technical support and all the study participants for their contribution.

\section{Author details}

IInstitute of Epidemiology and Medical Biometry, Ulm University, Helmholtzstr. 22, Ulm 89081, Germany. ${ }^{2}$ Departement of Diagnostic and Interventional Radiology, Ulm University, Prittwitzstrasse 43, Ulm 89075, Germany. ${ }^{3}$ Clinic Ludwigsburg, Posilipostr. 4, Ludwigsburg 71640, Germany.

Received: 27 June 2012 Accepted: 27 February 2013

Published: 7 March 2013

\section{References}

1. Breast cancer is the most frequent malignant tumor in women. http:// carestream.com/Specials/tradeshow/mammoScreening/pdf/Ingrid-english. pdf.

2. Emmert B, Gerstorfer M: Maligne Mammatumoren. In Crashkurs Gynäkologie: Repetitorium mit Einarbeitung der wichtigsten Prüfungsfakten. 1st edition. Munich: Elsevier Urban\&Fischer; 2005:286-287.

3. Boyd NF, Rommens JM, Vogt K, Lee V, Hopper JL, Yaffe MJ, Paterson AD: Mammographic breast density as an intermediate phenotype for breast cancer. Lancet Oncol 2005, 6:798-808.

4. Harvey JA, Bovbjerg VE: Quantitative assessment of mammographic breast density: relationship with breast cancer risk. Radiology 2004, 230:29-41.
5. Aitken Z, Walker K, Stegeman BH, Wark PA, Moss SM, McCormack VA, Silva Idos S: Mammographic density and markers of socioeconomic status: a cross-sectional study [abstract]. BMC Cancer 2010, 10:s35.

6. Boyd NF, Martin LJ, Bronskill M, Yaffe MJ, Duric N, Minkin S: Breast tissue composition and susceptibility to breast cancer. J Natl Cancer Inst 2010, 102:1224-1237.

7. Sauer G, Kreienberg R, Kurzeder C, Schreer I: Meaning of BI-RADS classification in breast diagnoses. Der Gynakologe 2006, 39:513-523.

8. Garrido-Estepa M, Ruiz-Perales F, Miranda J, Ascunce N, González-Román I, Sánchez-Contador C, Santamariña C, Moreo P, Vidal C, Peris M, Moreno PM Vaquez-Carrete JA, Collado-Garcia F, Casanova F, Ederra M, Salas D, Pollan M: Evaluation of mammographic density patterns: reproducibility and concordance among scales [abstract]. BMC Cancer 2010, 10:\$485.

9. Yaffe M, Boyd N: Mammographic breast density and cancer risk: the radiological view. Gynecol Endocrinol 2005, 21:6-11.

10. Vachon CM, Sellers TA, Janney CA, Brandt KR, Carlson EE, Pankratz VS, Wu FF, Therneau TM, Cerhan JR: Alcohol intake in adolescence and mammographic density. Int J Cancer 2005, 117:837-841.

11. Tseng M, Sellers TA, Vierkant RA, Kushi LH, Vachon CM: Mediterranean diet and breast density in the Minnesota Breast Cancer Family Study. Nutr Cancer 2008, 60:703-709.

12. Roddam AW, Spencer E, Banks E, Beral V, Reeves G, Appleby P, Barnes I, Whiteman DC, Keyal TJ: Reproducibility of a short semi-quantitative food group questionnaire and its performance in estimating nutrient intake compared with a 7-day diet diary in the million women study. Public Health Nutr 2005, 8:201-213.

13. Brisson J, Verreault R, Morrison AS, Tennina S, Meyer F: Diet, mammographic features of breast tissue, and breast cancer risk. Am J Epidemiol 1989, 130:14-24.

14. Nagel G: Primärprävention und Anwendung von Versorgungsleitlinien bei malignen Erkrankungen: Schwerpunkt Mammakarzinom. In PhD thesis. Ulm University, Institute of Epidemiology and Medical Biometry; 2007.

15. Ruf T, Nagel G, Altenburg HP, Miller AB, Thorand B: Food and nutrient intake, anthropometric measurements and smoking according to alcohol consumption in the EPIC Heidelberg Study. Ann Nutr Metab 2005, 49(1):16-25.

16. Keil U, Chambless LE, Döring A, Filipiak B, Stieber J: The relation of alcohol intake to coronary heart disease and all-cause mortality in a beerdrinking population. Epidemiology 1997, 8:150-156.

17. Cottet V, Touvier M, Fournier A, Touillaud MS, Lafay L, Clavel-Chapelon F, Boutron-Ruault MC: Postmenopausal breast cancer risk and dietary patterns in the E3N-EPIC prospective cohort study. Am J Epidemiol 2009, 170:1257-1267.

18. Altman DG: Some common problems in medical research. In Practical Statistics for Medical Research. 1st edition. London: Chapman and Hall; 1991:396-435

19. Vachon CM, Kushi LH, Cerhan JR, Kuni CC, Sellers TA: Association of diet and mammographic breast density in the Minnesota breast cancer family cohort. Cancer Epidemiol Biomarkers Prev 2000, 9:151-160.

20. Masala G, Ambrogetti D, Assedi M, Giorgi D, Del Turco MR, Palli D: Dietary and lifestyle determinants of mammographic breast density. A longitudinal study in a Mediterranean population. Int J Cancer 2006, 118:1782-1789.

21. Cade JE, Taylor EF, Burley VJ, Greenwood DC: Does the Mediterranean dietary pattern or the Healthy Diet Index influence the risk of breast cancer in a large British cohort of women? Eur J Clin Nutr 2011, 65(8):920-928.

22. Nagata C, Matsubara T, Fujita H, Nagao Y, Shibuya C, Kashiki Y, Shimizu H: Associations of Mammographic Density with Dietary Factors in Japanese Women. Cancer Epidemiol Biomarkers Prev 2005, 14:2877-2880.

23. Simopoulos AP: Essential fatty acids in health and chronic disease. Am J Clin Nutr 1999, 70:560S-569.

24. Nagel G, Mack U, Von Fournier D, Linseisen J: Dietary phytoestrogen intake and mammographic density - results of a pilot study. Eur J Med Res 2005, 10(9):389-94.

25. Bérubé S, Diorio C, Brisson J: Multivitamin-multimineral supplement use and mammographic breast density. Am J Clin Nutr 2008, 87:1400-1404.

26. Huang HY, Caballero B, Chang S, Alberg A, Semba R, Schneyer C, Wilson RF, Cheng TY, Prokopowicz G, Barnes GJ 2nd, Vassy J, Bass EB: Multivitamin/ mineral supplements and prevention of chronic disease. Evid Rep Technol Assess 2006, 139:1-117.

27. Tseng M, Byrne C, Evers KA, Daly MB: Dietary intake and breast density in high-risk women: a cross-sectional study [abstract]. Breast Cancer Res 2007, 9:s72. 
28. Flom JD, Ferris JS, Tehranifar P, Terry MB: Alcohol intake over the life course and mammographic density. Breast Cancer Res Treat 2009, 117:643-651.

29. Maskarinec G, Takata Y, Pagano I, Lurie G, Wilkens LR, Kolonel LN: Alcohol consumption and mammographic density in a multiethnic population. Int J Cancer 2006, 118:2579-2583.

30. Cabanes A, Pastor-Barriuso R, García-López M, Pedraz-Pingarrón C, SánchezContador C, Vázquez Carrete JA, Moreno MP, Vidal C, Salas D, Miranda-García J, Peris M, Moreo P, Santamariña MC, Collado-García F, Gonzalez-Román I, Ascunce N, Pollan M: Alcohol, tobacco, and mammographic density: a population-based study. Breast Cancer Res Treat 2011, 129(1):135-147.

31. Gapstur SM, López P, Colangelo LA, Wolfman J, Van Horn L, Hendrick RE: Associations of breast cancer risk factors with breast density in Hispanic women. Cancer Epidemiol Biomarkers Prev 2003, 12:1074-1080.

32. Yu H, Berkel J: Do insulin-like growth factors mediate the effect of alcohol on breast cancer risk? Med Hypotheses 1999, 52:491-496.

33. Dal Maso L, La Vecchia C, Augustin LS, Mantzoros CS, Kendall CW, Franceschi S: Relationship between a wide range of alcohol consumptions, components of the insulin-like growth factor system and adiponectin. Eur J Clin Nutr 2007, 61:221-225.

34. Gill J: The effects of moderate alcohol consumption on female hormone levels and reproductive function. Alcohol Alcohol 2000, 35:417-423.

35. Yong M, Atkinson C, Newton KM, Aiello Bowles EJ, Stanczyk FZ, Westerlind KC, Holt VL, Schwartz SM, Leisenring WM, Lampe JW: Associations between endogenous sex hormone levels and mammographic and bone densities in premenopausal women. Cancer Causes Control 2009, 20:1039-1053.

36. Nagel G, Zoller D, Ruf T, Rohrmann S, Linseisen J: Long-term reproducibility of a food-frequency questionnaire and dietary changes in the European Prospective Investigation into Cancer and Nutrition (EPIC)Heidelberg cohort. Br J Nutr 2007, 98:194-200

doi:10.1186/1471-2458-13-203

Cite this article as: Voevodina et al:: Association of Mediterranean diet, dietary supplements and alcohol consumption with breast density among women in South Germany: a cross-sectional study. BMC Public Health 2013 13:203.

\section{Submit your next manuscript to BioMed Central and take full advantage of:}

- Convenient online submission

- Thorough peer review

- No space constraints or color figure charges

- Immediate publication on acceptance

- Inclusion in PubMed, CAS, Scopus and Google Scholar

- Research which is freely available for redistribution 